\title{
Public Libraries as Aids to Sense Making in Urban Aboriginal Populations
}

\section{Monique Woroniak}

\begin{abstract}
Aboriginal peoples in Canada increasingly reside in areas outside of their designated reserve lands, with large numbers living in many of the country's Census Metropolitan Areas. This paper discusses the potential for public libraries to aid Aboriginal peoples' sense making efforts in urban environments. A statistical portrait of urban Aboriginals peoples is provided, along with a description of selected, key cultural values. Karl E. Weick's seven properties of organizational sense making (as outlined by Chun Wei Choo) are applied in a discussion of how public libraries could better support urban Aboriginal populations. Finally, the work of the Albert branch library in Regina is described as a successful example in the provision of such support.
\end{abstract}

\footnotetext{
About the Author(s): Monique Woroniak is a first year MLIS student at Dalhousie's School of Information Management (SIM). She holds a Bachelor of Arts (Honours) from the University of Manitoba, with a major in Political Studies. Her research interests revolve around library services and information provision for Aboriginal peoples. This paper was written for SIM's Information in Society course.
} 


\section{Introduction}

"Frustrations, loneliness, unemployment, poor housing accommodation, drinking, trouble with the law and a social aid system that does nothing more but barely keep body and soul together..."(Dieter, 1973). Found in a February 1973 volume of Saskatchewan Indian, this quotation expressed the plight of urban Aboriginal peoples living in Regina; over thirty years later it is a description that remains true for much of Canada's urban Aboriginal population.

Aboriginal peoples are increasingly living in areas outside of their designated reserves. While exceptions do exist, many of these individuals are ill-equipped for life in the cities. Many lack the literacy skills required to function in fast-paced urban environments. They find themselves excluded from the opportunities that exist for those with higher levels of education. The fact that they make up a minority of the population in the cities means there are limited opportunities for them to engage in the traditions of their culture. When they walk down a street - more often than not - the faces they see do not look like their own.

The feelings of exclusion and bewilderment expressed in the opening paragraph are the basis for the application of theory and solutions offered in this paper. To begin, a statistical picture of the circumstances urban Aboriginal peoples face will be provided. The ways in which they attempt sense making - and the challenges of that process - will be discussed via an application of Karl E. Weick's seven properties of organizational sense making as outlined by Chun Wei Choo.

It will then be argued that public libraries can aid urban Aboriginal peoples' sense making efforts by creating spaces where Aboriginal peoples can see themselves and their culture reflected in an urban environment. This work will also be discussed in the context of the properties of sense making. Finally, an overview of a successful example of a public library's service provision to an urban Aboriginal population will be overviewed.

\section{Demographics}

\section{Aboriginal peoples as percentage of metropolitan populations}

The Aboriginal Peoples Survey 2001 reported that approximately 713,000 Aboriginal people were living off reserve, and that this number represented over 70 percent of the Aboriginal population of Canada. Most members of this group (68 percent) lived in urban areas, with 40 percent of the off-reserve Aboriginal population living in census metropolitan areas (CMAs) or cities with a population greater than 100,000 . With the exception of Nunavut (where Aboriginal peoples comprised 85 percent of the population) the provinces with the greatest, relative, population of non-reserve Aboriginal peoples were in the West - in particular Manitoba and Saskatchewan where the group comprised 9 percent and 10 percent of the total population, respectively (O'Donnell and Tait, 2003, p. 8). 
These figures reflect a significant growth in the real numbers of urban Aboriginal peoples living in CMAs. Again, Manitoba and Saskatchewan are exceptional in this regard. In their report Aboriginal Conditions in Census Metropolitan Areas 1981-2001, Siggner and Costa (2005) note that Winnipeg experienced a nearly 250 percent increase in its Aboriginal population with real numbers increasing from 16,000 to 56,000; in Saskatoon there was a 382 percent increase, with the Aboriginal population growing from 4,200 to over 20,000 (p.13).

\section{Age}

In addition to "growing," another word that aptly describes Canada's Aboriginal population is "young". In 2001, nation-wide, 33.2 percent of Aboriginal peoples were 14 years of age or younger, and 17.3 percent were age 15-24 (Siggner and Costa, 2005, p.16). This is a group whose absolute numbers in CMAs are also increasing, so much so that Aboriginal children under the age of 14 account for between 30 and 40 percent of the total Aboriginal populations in most Western (i.e. Winnipeg, Regina, Saskatoon, Calgary, Edmonton and Vancouver) CMAs (Siggner and Costa, 2005, pp. 5-16). In the select Western CMAs of Winnipeg, Regina and Saskatoon those numbers translate into Aboriginal children under the age of 15 comprising 14-16 percent of all children in those cities (Siggner and Costa, 2005, p.16).

While seniors comprise a decided minority of the urban Aboriginal population, their numbers particularly in select Western cities - have significantly increased as well. In Winnipeg, for example, from 1981-2001 the number of Aboriginal seniors increased from 320 to upwards of 1,800 . It is also noted that there has recently been a "significant improvement" in the life expectancy of Aboriginal peoples, and a concurrent drop in their fertility rates, which means that the population is aging, but much more slowly than non-Aboriginal groups (Siggner and Costa, 2005, p.16).

\section{Employment}

A recent Statistics Canada release paints a bleak picture of urban Aboriginal peoples' employment rates and prospects. For the 12 months ending in March, 2005 unemployment rates for urban Aboriginal peoples in the West were, on average, 2.5 times higher than those of their non-Aboriginal counterparts. While it is reported that the unemployment rate for urban Aboriginal people decreased slightly from 2001-2005, the current rate of 13.6 percent remains more than double that of non-Aboriginals. When Aboriginal youth are considered separately, the statistics are equally discouraging, with an unemployment rate of 20.8 percent compared to 10 percent for non-Aboriginal youth (Statistics Canada, 2005).

For those urban Aboriginal peoples who were employed, their earning power significantly trailed that of non-Aboriginals; for example, an Aboriginal person living in Winnipeg in 2000 earned $\$ 68$ for every $\$ 100$ earned by a non-Aboriginal individual (Siggner and Costa, 2005, p. 21). 


\section{Family}

Aboriginal Conditions in Census Metropolitan Areas also addresses the family-related considerations of Aboriginal peoples in CMAs, citing the Aboriginal Peoples Survey of 2001's finding that 40 percent of Aboriginal peoples who moved to a CMA from 1996-2001 did so for family-related reasons (Siggner and Costa, 2005, p. 23). Once they arrive in a CMA, the family structure of many Aboriginal peoples is similar, with significant numbers of households being headed by a single parent. This is particularly true for the cities of Winnipeg, Regina and Saskatoon where over half of Aboriginal children lived in single-parent households in 2001, a number that is even more striking when compared with a range of 17 percent to 19 percent for non-Aboriginals in those cities (Siggner and Costa, 2005, p.17).

\section{Literacy levels}

Literacy rates among urban Aboriginal peoples have been found to be lower than for nonAboriginals. The International Adult Literacy and Skills Survey (IALSS), (the Canadian section of the Adult Literacy and Life Skills study, a cooperative undertaking of the Government of Canada, the United States National Centre for Education and Statistics and the Organization for Economic Co-operation and Development) found that 60 percent of the urban Aboriginal populations in Manitoba and

Saskatchewan scored below a Level Three in a measurement of prose (i.e. "continuous text" as found in books or newspapers) literacy skills. This was compared to a statistic for nonAboriginal individuals of 45 percent and 39 percent for those two provinces, respectively. The IALSS rates literacy skills according to a Five-level scale, with Level One constituting the lowest ability level and Level Five the highest; for developed countries such as Canada, literacy abilities corresponding to

Level 2 or higher are "generally associated with a number of positive outcomes such as increased employment opportunities and higher civic participation" (Statistics Canada, 2005, November 9).

\section{Education levels}

The Aboriginal Peoples Survey 2001 offers some insight into the levels of education possessed by urban Aboriginal peoples. In 2001, 48 percent of Aboriginal peoples residing offreserve, aged 20-24, had "incomplete secondary school" as their highest level of education (this was compared with 26 percent for non-Aboriginals in the same age group). However, statistics also showed reason for optimism. In 2001, 39 percent of urban Aboriginals peoples aged 25-44 had completed post-secondary studies - this was an increase of five percent from 1996 census data (O'Donnell and Tait, 2003, pp. 18-19). This is a positive trend because, as Siggner and Costa (2005) note, "in 2001, as long as Aboriginal young adults completed their 
university degrees, their employment rates in CMAs were on par with their Aboriginal counterparts" (p. 24).

\section{Income}

The overall picture remains bleak, however, with all of the above factors contributing to high poverty rates. In 2000 Aboriginal peoples living in all of Canada's CMAs had a low-income rate of 41.6 percent, compared to 17.3 percent for non-Aboriginals. Again, the statistics were particularly negative in Western CMAs, with Winnipeg's Aboriginal population seeing 3.7 percent increase in its low-income rate. Regina and Saskatoon's Aboriginal populations reported low-income rates approximately four times higher than the non-Aboriginal population (Heisz and McLeod, 2004, pp.33-34).

\section{Sense making and urban Aboriginal peoples' experience}

"The requirements of survival in the city frequently force Aboriginal people to change their way of life and reshape the way they express their beliefs and values. The resulting adaptations run a complete range, from maintenance of a strong Aboriginal identity based on traditional Aboriginal culture to assimilation into the pervasive non-Aboriginal culture. In integrating themselves into an urban environment, most Aboriginal people fall between these two extremes. Some remain trapped between worlds, unable to find their place in either culture; this often creates tension, alienation and identity confusion." (Royal Commission on Aboriginal Peoples, 1996, Vol. 4).

The following analysis of Weick's seven properties of sense making speaks to the challenges urban Aboriginal people face with respect to issues ranging from identity construction to basic physical survival, upon arriving in a city, and, even, long after their arrival. Their sense making reflects efforts to interact with, negotiate within, survive, and hopefully succeed, in a complex environment.

\section{Sense making and identity construction}

The first of Weick's properties is that sense making is grounded in identity construction. Engaging in sense making aids individuals in maintaining a self-identity. This is an active part of the process, with individuals simultaneously reacting and shaping their environment. Choo points out that individuals will work to influence others' behaviour towards them, even while they are attempting to piece together a self-identity based on the behaviour or reactions they garner (Choo, 1998).

This first property of sense making presents, perhaps, the largest challenge for the urban Aboriginal population, and has the most influence on their success or failure in urban environments. Although the number of Aboriginal peoples in urban centres is growing, they still comprise a minority of the total population. As a result, cities become environments where 
Aboriginal peoples are not likely to see expressions of themselves or their culture. This is to say nothing of the racism they often face. In the best of possible scenarios, Aboriginal peoples have had positive exposure to their culture, language and traditions. If they have, then there is a good chance they are arriving in a city with a relatively strong self-identity. However, if they have not been able to engage with their culture, and they then arrive in a foreign, urban environment, "maintaining a consistent self-conception" becomes even more of a challenge (Choo, 1998). Even for the individuals who arrive with a strong knowledge of their culture, sense making in an urban, non-Aboriginal environment is a difficult process. For those who arrive without that grounding, the process of positive engagement with their new surrounding may seem impossible.

\section{Sense making as retrospective}

The second property as outlined by Choo is that sense making is retrospective. In this part of the process an individual "attends to events that have already taken place" (Choo, 1998, p. 69). This is a concept that can apply to urban Aboriginal peoples in several respects. If sense making is a process that, in part, happens through interpreting past experiences and applying those interpretations to present situations, then this aspect of the process also presents a challenge for urban Aboriginal peoples. One scenario is that they have never been to an urban centre before and therefore have no prior knowledge on which to base their decisions and actions in the new environment. A second possibility is that they have previously been in a city, and so have experiences to reflect upon and incorporate into their engagement processes. The nature of their past experiences then becomes very important. If those experiences were positive, Aboriginal peoples may feel more optimistic about their prospects in the new environment. If the experience was more negative (and many of the statistics suggest this is a likely case) then the individuals engage (or not) and interpret the environment in a way that demonstrates (and reinforces) their "outsider" status.

\section{Sense making as enactive}

The third property of sense making is that it is enactive. In order to comprehend the environment, people work to actually produce a part of the environment in which they find themselves. Often they will do this by "breaking up streams of experience" in order to address the challenges of being in a new or changing situation. The other action people may undertake is to actually physically or structurally change the environment so that they may more effectively engage with it (Choo, 1998, p. 69).

Breaking up the experiences in cities is a tactic employed, perhaps almost subconsciously, by many Aboriginal peoples. Just as many non-Aboriginals label certain neighbourhoods or groups of people as desirable or not, so too do Aboriginal peoples come to learn which neighbourhoods, services and organizations are welcoming to them and reflective of their cultural and other needs. Being able to undertake action to bring about change in the 
environment is a very powerful aspect of sense making. It can require networks of support, political or economic clout, and, certainly, a strong self-identity. All of these requirements make this aspect of sense making a difficult endeavour for most urban Aboriginals peoples.

\section{Sense making as social}

The fourth property of sense making is that it is social. Choo (1998) is explicit in reinforcing this point - whether a person looks to be alone or not, all sense making is done within the context of social groups, with individuals taking into account the reactions of, and their interactions with, other people in the environment. It is also noted that individuals consider "the reaction of others not physically present, but who will be affected or whose reactions will be important (Choo, 1998, p. 69).

The Royal Commission on Aboriginal Peoples (RCAP) speaks to this point in its discussion of the importance of family to Aboriginal peoples generally and urban Aboriginal peoples specifically. Despite a lack of contact with their families, RCAP recognizes that some urban Aboriginal peoples will recall the lessons they have been taught as part of an underlying sense of obligation to their families (RCAP, 1996).

However, to the extent that Aboriginal peoples feel isolated when they arrive in a city (i.e. they may be arriving on their own, they automatically become part of a minority group, etc.) their sense making abilities are stunted. If sense making, as Choo (1998) explains, takes place when groups of people are "engaged in talk, discourse, and conversation," then urban Aboriginal peoples successful implementation of this property is largely dependent on their ability to find others willing to engage with them socially (p. 69). The extent to which this is possible varies from individual to individual with respect to whether or not they already know others in a city, but success in the social aspect of sense making is also dependent upon the abilities and influence of the individuals that make up an Aboriginal person's social group. Even when they are able to seek out one another to engage in discourse, this alone may not be sufficient to achieve the enactive, transformative processes of sense making.

\section{Sense making as ongoing}

The fifth property of sense making is that it is ongoing. This is a relatively apparent characteristic of the process. Individuals are constantly engaged in activities whose goal is to help them understand their environment and their place in it. Choo (1998) does note that while the process is ongoing, it can be interrupted, often with the consequence of producing emotional responses.

Like all individuals, urban Aboriginal peoples are constantly interacting with their environment, and with varying degrees of success and satisfaction. The act of an Aboriginal person arriving for the first time in a city may, in and of itself, constitute the most significant sense making "interruption" they have ever experienced. For others, who have lived in a city previously, or 
who have been residents for some time, their minority status results in a kind of stop-start quality to their sense making. How far along the process is able to progress - and the frequency of interruptions it encounters - is, again, dependent upon the networks, past experiences and skills unique to each Aboriginal person.

\section{Sense making and extracted cues}

The sixth property of sense making is that it is both focused on - and becomes focused by extracted cues. These cues are the "familiar structure" upon which individuals may base their sense making. These structures become the starting points of much of individuals' comprehension of, and engagement with, their environment (Choo, 1998, p. 69).

This property of sense making is extremely salient to the experiences of urban Aboriginal peoples. Cities often offer little in the way of familiar (i.e. Aboriginal) cultural cues, a situation which results in many urban Aboriginal peoples lacking starting or reference points from which to begin successful engagement with their environments. The extraction of cues has a strong connection with the retrospective aspect of sense making. Choo (1998) explains that the exploitation of cues is the result of "scanning, searching, or noticing" (p. 69). The ability to seek out cues is obviously essential to the sense making process, but it is one that can be hindered by an interpretation of the environment based on sense making's retrospective quality.

If Aboriginal peoples arrive in a city, and it is not their first time in an urban environment, the nature of their scanning process will be affected by past experiences. The locales they scan for cues may be influenced by how positive or negative their past interactions were in a given neighbourhood, building or organization. Indeed, depending on the success of previous scanning attempts, an Aboriginal person may or may not spend a significant amount of time looking for the familiar in an urban environment.

\section{Sense making as focused on plausibility}

The final property of sense making is that it is informed by plausibility as opposed to accuracy. This property speaks to the practical nature of individuals in a world where fixed meanings are less and less the norm, and "politics of interpretation, and conflicting interests" need to be navigated on an ongoing basis (Choo, 1998, p. 70).

This aspect of sense making speaks to the reality that many Aboriginal peoples are not in a position to strategize their sense making efforts. Whether returning to a city, or arriving for the first time, often the decisions that need to be made are urgent in nature (e.g., regarding housing) and do not afford the luxury of a thorough scan of the environment, regardless of the fact that there may be nothing familiar or helpful in obvious sight.

\section{Cultural considerations}




\section{A holistic view}

Establishing a definition of Aboriginal culture is a difficult task - and one outside the scope of this paper. In the initial paragraphs of its section on Aboriginal culture, The Report of the Aboriginal Justice Inquiry of Manitoba compares trying to describe Aboriginal culture with attempts at describing Canadian culture - both present a challenge because they are informed by heterogeneous groups (Aboriginal Justice Implementation Commission, 1999). However, there is one overarching characteristic that is common to the cultural outlook of Canada's Aboriginal peoples, and that is a view of the world that is total, or holistic in nature. According to James Dumont, in today's Aboriginal communities "everything begins with a holistic vision, that generates a respect that comes from understanding the intrinsic wonder of creation, knowledge, wisdom and the dignity and freedom of others" (Hodson, 1994).

In considering the importance of oral tradition and the role of elders in Aboriginal culture - and how both can be supported and utilized by public libraries - it is important to remember the holistic outlook guiding the traditions and their practices.

\section{Oral tradition}

One of the most essential aspects of Aboriginal cultures is what is known as "oral tradition." In her article on the subject, Maureen Simpkins cites how Julie Cruikshank differentiates the concept from "oral history." While it is conceded that, in practice, definitions of the two terms become more fluid, strictly speaking "oral history" is the first hand account of an experience by a witness, while "oral tradition" refers to the practice and process of transferring information from generation to generation (Simpkins, n.d., p. 263).

Oral histories and oral tradition are such a critical part of Aboriginal cultures because they encapsulate and transmit the culture's knowledge, which, in and of itself, is comprised of traditional beliefs and values (Simpkins, n.d.). It is important to remember that the traditional knowledge (informed by the culture's beliefs and values) of Aboriginal peoples is, largely, distinct from mainstream, non-Aboriginal cultural values. The RCAP notes that Aboriginal traditional knowledge adheres to, and reinforces, the common cultural characteristic of a holistic view of the world, encompassing "ecological teachings, medical knowledge, common attitudes toward Mother Earth and the Circle of Life, and a sense of kinship with all creatures" (RCAP, 1996).

While there exists many different Aboriginal cultures within Canada, just as they share a holistic vision of the world, so too do they value - and even rely on - oral tradition in order to communicate the content of that knowledge, and their culture, within and amongst generations.

\section{Elders}


So there are in fact guides who have been there who have each individually lived through their own hell and have found their way and they are in fact guides. So if you are going into a strange land, and God knows, it's strange to so many young people. And they can avoid all that and ensure you a good trip. That's really what it is. It's that simple. Ojibway Elder Art Solomon (Steigelbauer, 1996, p. 42)

The communication of traditional knowledge and the maintenance of oral tradition are intrinsically linked to the role elders play in Aboriginal cultures. As the above quote attests, they are the guides and teachers for many Aboriginal people, and the typical method for communicating cultural teachings is by way of oral tradition, specifically storytelling. While the exact meaning of the term "elder" varies amongst

Aboriginal cultures and communities, it most commonly refers to someone who is older, and/or someone who has been sought out for spiritual and cultural leadership as well as for their knowledge of some aspect of tradition (Steigelbauer, 1996). Of particular relevance to urban Aboriginal peoples is the notion that, historically, elders have acted as a "bridge" between the ancient aspects of their cultures and modern influences (Aboriginal Justice Implementation Commission, 1999). This quality, in particular, makes the inclusion of elders in any kind of programs or services for urban Aboriginal peoples, essential.

\section{Public libraries and possibilities for aiding sense making}

So how should all of the above factors - urban Aboriginal peoples' demographic profile, a holistic cultural viewpoint, importance of oral tradition and the valuing of elders' contributions affect the approach public libraries take in providing programs and services for urban Aboriginal populations? The well of Aboriginal culture is deep, providing many lessons and techniques to incorporate into an approach to service which could aid urban Aboriginal peoples in their sense making efforts as cultural minorities in our cities.

Public libraries can begin by facilitating urban Aboriginal peoples' construction of positive selfidentities. One of the best ways of doing this would be to make the public library a place where members of Aboriginal communities see themselves, and their cultures, reflected. This can be done through programming based on Aboriginal culture and traditions, through the acquisition of Aboriginal-related materials, and through the incorporation of the various symbols of Aboriginal cultures in the library's physical space.

In so far as the construction of positive identities is affected by the reactions people garner from others, public libraries should aim to be welcoming spaces for Aboriginal peoples. The importance of this point cannot be overstated. It is essential that urban Aboriginal patrons are made to feel that the library is a place where they belong and where their culture, as well as their own value as citizens, is reaffirmed. 
Public libraries can also have a significant effect on the retrospective aspect of the sense making process. If urban Aboriginal peoples are made to feel welcome in the library, if they see their culture being reflected in the physical space and services, they are more likely to look back on their experience in a positive light. This affect is important for two reasons: first, if their experience has been a good one, an Aboriginal person is more likely to return to the library, and second, they will be more likely to tell other members of their community about the benefits the institution has to offer. In providing a welcoming space for urban Aboriginal peoples, public libraries would not only establish themselves as being supportive of Aboriginal cultures, they would also help to establish the reputation of cities at-large as being more willing and able to address the concerns of Aboriginal peoples.

Public libraries could also play a vital role in the enactive processes of sense making. Whether or not they are newly arrived in a city, Aboriginal peoples have a significant amount of new information to navigate their way through. While the level of ability to process and manipulate the culture of a non-Aboriginal urban environment may vary from individual to individual, public libraries can aid the process by offering programs that "bracket" aspects of city life (e.g. housing, education/training, entertainment, etc.) through instructional programming that is culturally relevant to urban Aboriginal peoples. This "bracketing" approach should not be seen as working against Aboriginal cultures' holistic viewpoints, as long as all aspects relevant to the individuals' well-being are being addressed by the programs and services of the library. Adopting a holistic approach to programming would mean the library would need to include offering related to, not only literacy and job training, but also physical and spiritual well-being.

For many non-Aboriginal Canadians their public library is as much a social hub as an information provider and repository. While there are not insignificant numbers of Aboriginal organizations in Canada's cities, many of whom offer opportunities for Aboriginal peoples to build and solidify social contacts, public libraries should not hesitate to count themselves among those providers for this group. Whether by offering meeting space, organized programming, or simply by making Aboriginal peoples aware that the library is a place where they are always welcome to come and share conversation and ideas with one another, the public library - as a free, public institution - would make an ideal gathering place for urban Aboriginal peoples.

There is another possible benefit in public libraries support of this part of the sense making process, and that is in the facilitating of Aboriginal peoples' relations with the non-Aboriginal community - in essence, broadening the scope of social contact for both groups. With public libraries still, largely, existing as middle class, and -certainly - non-Aboriginal institutions, the inclusion of Aboriginal peoples in the activities of the library means an increase in the likelihood of cultural exchange (formally organized through programming, or through informal means) between the two groups. This broadening of the social sphere, while certainly a benefit to non-Aboriginals, is of particular advantage to urban Aboriginal peoples whose success in a 
city can be helped by establishing relationships with non-Aboriginals based on respect and cultural exchange.

The ongoing property of sense making fits particularly well with the concept of the public library. As institutions, public libraries are relatively stable entities. That is to say, they have been in existence in most urban centres for a significant period of time, and - while they may deal with threats to their funding, and questions about the viability of their various branches they are more stable than certain non-profit organizations or other special initiatives (e.g., committees, taskforces, etc.) which also may be involved in providing services to urban Aboriginal peoples. While it remains important that public libraries continue to evolve and work to improve the services they provide, it is of definite benefit to Aboriginal peoples that these organizations are seen to be, and largely supported as, important service-providers in our cities. As such, they are well-positioned to support the ongoing sense making efforts of urban Aboriginal peoples.

If sense making is said to be centred around, and derived from environmental cues, then, again, public libraries are ideally positioned to aid the sense making process. Choo (1998) speaks of cues as being "points of reference or starting nodes from which ideas may be linked and connected into networks of meaning" (p. 69). By providing relevant services and supports, public libraries can act as the "nodes" which urban Aboriginal peoples can come to rely on to help them construct positive self-identities, build upon social networks and enable them to enact upon the urban environment.

Finally, with respect to sense making often being informed by plausibility, (particularly as chosen over accuracy), public libraries, with their relatively stable presence, can act as an information provider to urban Aboriginals regarding some their most basic - often urgent needs (i.e. shelter, medical care, child care, etc.). The library should have current, accurate information regarding the provision of these services on hand for Aboriginal peoples to access. While there may be other outlets that provide this information, as a "neutral" actor in this context (i.e., as an institution mandated to provide access to the broadest range of information possible) the library is ideally positioned to ensure urban Aboriginal peoples - while possibly acting out of sheer plausibility (i.e., survival) - are also able to receive accurate information to aid them in their sense making.

\section{An example of success}

The Albert Library in the city of Regina is an example of a public library that is succeeding in facilitating and advancing the sense making efforts of the urban Aboriginal peoples it services. In meeting this goal, the Albert Library employs a holistic vision of its community, incorporates Aboriginal oral tradition and values the contributions of elders. 
The library has been serving its neighborhood since 1913, but undertook an overhaul of its mandate after a 1979 report for the Regina Public Library Board recommended reducing its hours due to low circulation levels. The report became the impetus for the creation of the community advisory committee which serves the library to this day. Committee membership is open to anyone living or working in the library's catchment area of North Central Regina, and plays a key role in decisions regarding the library's staffing, programming and collection development (Sinclair and Muir, 2000).

An example of the holistic vision employed by the library is that its Branch Head is directed to participate in organizations serving the North Central community - the library benefits from garnering additional feedback about its operations and from being able to tailor, and promote, its programming to the community (Sinclair and Muir, 2000).

The Albert Library also recognizes and reaffirms the importance of Aboriginal oral tradition through the incorporation of storytelling programming. While the concept of storytelling in a library setting may not appear innovative on the surface, the programming offered at the library is anything but typical "storytime."

One of the many achievements of the Albert Library Committee was a grant that was secured to host a Storyteller in Residence Project which had its own, dedicated Aboriginal traditional teacher as a resource. Utilizing, again, a holistic approach the library further integrated Aboriginal oral tradition into its overall programming, taught young people how to collect and record oral histories (and helped publish the material collected) and organized community day trips to some of Saskatchewan's reserves to incorporate further cultural teachings (Sinclair and Muir, 2000).

In providing advice for projects like the above, and also regarding the staffing and collections development of the library, elders play a vital role at the Albert branch. In speaking about their role in Aboriginal cultures, Chief Harry Lafond stated that "elders are known for their knowledge to educate. They become walking, talking libraries and carriers of information about the culture" (Sinclair and Muir, 2000). Recognized as such, elders are consulted about both the ongoing operation of the library, and for more special events, such as the Library's 80th anniversary when an elder presented the library with its own, unique spiritual colours (Sinclair and Muir, 2000).

These are just a few examples of how the Albert Library incorporates some of the main characteristics of Aboriginal cultures in aiding the sense making processes of its community's members. In employing these and other innovations, the Library is working to create a space where urban Aboriginal peoples see themselves and their culture reflected within a city where they make up a minority - albeit growing - of the population. The Albert branch creates a positive library experience, offering a social space for the Aboriginal peoples in the community, and one where they also come together to learn about their own cultures and are exposed to 
education and training necessary to increase their opportunities within the urban environment. In this way the library succeeds in supporting urban Aboriginals' ability to express their concerns and to enact to bring about change in their surroundings. In adopting a new vision of what was possible for its operations over 25 years ago, the Albert Library has succeeded in becoming a "seed" for its community, growing for its members a space of both support for individuals and cultural resonance - themselves inextricably linked.

\section{Conclusion}

As the presence of Aboriginal peoples in Canada's metropolitan areas continues to grow, there will be a concurrent growth in the need for municipalities to address the needs of this segment of the population so that they - particularly as a group with many young people - will be better equipped to contribute to the social and cultural life of our cities. As the sense making capacity of urban Aboriginal peoples improves in these spheres, it is plausible to believe that their economic and political strength may also grow. In aiding the sense making efforts of Aboriginal peoples, public libraries can contribute to the above goal. As institutions of public good, the onus is on libraries to reflect the interests, and serve the needs of the communities who can, or would, access its offerings. As the demographic of Canadian cities shifts (particularly in Western CMAs), so too must public libraries alter their approaches to collections building, programming and collaboration with outside groups. This work is essential if the institutions wish to remain relevant societal hubs - and, in many (if not all) Canadian cities, it is work that must address the unique sense making needs of our country's urban Aboriginal peoples. 


\section{References}

Aboriginal Justice Implementation Commission, 1999. "Aboriginal Concepts of Justice," In: Report of The Aboriginal Justice Inquiry of Manitoba: Vol.1. The Justice System and Aboriginal People, at http://www.ajic.mb.ca/volumel/chapter2.html, accessed 5 November 2005.

C.W. Choo, 1998. "The Management of Ambiguity - Organizations as Sense-Making Communities," In: The Knowing Organization. How Organizations Use Information to Construct Meaning, Create Knowledge, and Make Decisions. New York: Oxford University Press, pp. 65104.

M. Dieter, 1973. "Urban Indians: Victims of Rural Poverty Become Victims Of Urban Poverty," Saskatchewan Indian, volume 3, number 2, at http://www.sicc.sk.ca/saskindian/a73feb12.htm, accessed 9 November 2005.

A. Heisz and L. McLeod, 2004. Low-income in Census Metropolitan Areas, 1980-2000. Ottawa: Minister of Industry, at http://www.statcan.ca/english/research/89-613MIE/2004001/89-613-MIE2004001.pdf, accessed 4 November 2005.

J. Hodson, 1994. "Native Education at Georgian College," College Quarterly, volume 1, number 4, at http://www.collegequarterly.ca/1994-vol01-num04-summer/hodson.html, accessed 4 November 42005.

V. O'Donnell and H. Tait, 2003. Aboriginal Peoples Survey 2001 - initial findings: Well-being of the non-reserve Aboriginal Population. Ottawa: Minister of Industry, at http://www.statcan.ca/english/freepub/89-589-XIE/89-589-XIE2003001.pdf, accessed 4 November 2005.

Royal Commission on Aboriginal Peoples, 1996. "Education," In: Report of the Royal Commission on Aboriginal Peoples: Vol. 3. Gathering Strength, at http://www.aincinac.gc.ca/ch/rcap/sg/si50_e.html\#7. Elders, accessed 3 November 2005.

Royal Commission on Aboriginal Peoples, 1996. "Urban Perspectives," In: Report of the Royal Commission on Aboriginal Peoples: Vol. 4. Perspectives and Realities, at http://www.aincinac.gc.ca/ch/rcap/sg/sj1_e.html\#Perspectives and Realities, accessed 3 November 2005.

A.J. Siggner and R. Costa, 2005. Aboriginal Conditions in Census Metropolitan Areas, 19812001. Ottawa: Minister of Industry, at http://www.statcan.ca/english/research/89-613-MIE/89613-MIE2005008.pdf, accessed 9 November 2005.

W. Sinclair and R. Muir, 2000. Albert Library. One Canadian Inner City Library: Answering the Needs of the Community. Paper presented at the 2000 British Columbia Library Conference, http://www.lib.sk.ca/staff/bestpractices/albertalib.html, accessed 4 November 2005. 
M. Simpkins, n.d.. From Ear to Ear: Cross-Cultural Understanding of Aboriginal Oral Tradition, at http://www.oise.utoronto.ca/CASAE/cnf2002/2002_Papers/simpkins2002w.pdf, accessed 4 November 2005.

Statistics Canada, 2005. "Labour Force Survey: Western Canada's off-reserve Aboriginal population," In: The Daily, at http://www.statcan.ca/Daily/English/050613/d050613a.htm, 4 November 2005.

Statistics Canada, 2005. "International Adult Literacy and Skills Survey," In: The Daily, at http://www.statcan.ca/Daily/English/051109/d051109a.htm, 12 November 2005.

S. M. Steigelbauer, 1996. "What is an Elder? What do Elders do?: First Nation Elders as Teachers in Culture-Based Urban Organizations," In: The Canadian Journal of Native Studies, volume 16 number 1, pp.37-66 at http://www.brandonu.ca/Library/CJNS/16.1/Stiegelbauer.pdf, accessed 4 November 2005. 